\title{
Internamentos não voluntários civis por razão de transtorno psíquico na Catalunha: uma análise das decisões judiciais à luz da bioética
}

I ${ }^{1}$ Rachel Torres Salvatori, ${ }^{2}$ Carla Aparecida Arena Ventura I

Resumo: O internamento não voluntário por razão de transtorno psíquico é uma providência de caráter terapêutico que deveria assegurar tanto o direito do enfermo, de ser tratado dignamente, quanto a segurança dos demais indivíduos que o direito deve proteger. Entretanto, alguns investigadores têm chamado a atenção para a ocorrência de internamentos não completamente fundamentados em necessidades terapêuticas. Assim, este estudo teve como objeto a investigação da jurisprudência das Audiências Provinciais da Comunidade Autônoma da Catalunha, Espanha, sobre os pedidos de internamento não voluntário de pessoas portadoras de transtornos psíquicos. Os objetivos da pesquisa consistiram em descrever as variáveis apresentadas nas resoluções judiciais de 2 a Instância relacionadas aos internamentos não voluntários por razão de transtorno psíquico e analisar o posicionamento dos juízes à luz dos princípios bioéticos. Empregaram-se como método a estatística descritiva e a categorização por ideias centrais, de acordo com o Discurso do Sujeito Coletivo. Os juízes de $2^{2}$ Instância da Catalunha vêm se deparando com recursos impetrados por pessoas que pleiteiam o internamento de seus familiares próximos, alegando a internação como medida de proteção da própria pessoa que, na grande maioria dos casos, é diagnosticada como esquizofrênica. Foram identificadas 15 ideias centrais nas decisões judiciais, analisadas de acordo com os princípios da bioética principialista. O princípio da beneficência parece suplantar todos os outros nas decisões judiciais. Concluiu-se que não só o Poder Judiciário, mas também a sociedade, a medicina e o Estado têm papéis relevantes a serem desempenhados na abordagem dessa questão.
1 Enfermeira; mestre em Enfermagem na área da Saúde da Mulher pela Universidade do Estado do Rio de Janeiro; doutoranda do Programa de Enfermagem Psiquiátrica da Escola de Enfermagem de Ribeirão Preto (EERP USP). Endereço eletrônico: racsalvador@hotmail.com

2 Professora associada do Departamento de Enfermagem Psiquiátrica e Ciências Humanas da Escola de Enfermagem de Ribeirão Preto da Universidade de São Paulo/ Centro Colaborador da OMS para o Desenvolvimento da Pesquisa em Enfermagem. Endereço eletrônico: caaventu@eerp.usp.br 


\section{Introdução}

Em todo o mundo, aproximadamente 450 milhões de pessoas sofrem de algum transtorno mental ou comportamental (OMS, 2001). O envelhecimento e os problemas sociais, como a pobreza, a violência, as desigualdades e a agitação da vida moderna, tendem a elevar esse número, se considerarmos que os problemas mentais têm influências não só biológicas, mas também ambientais e sociais.

Com o advento dos movimentos de reformas psiquiátricas iniciados na metade do século $\mathrm{XX}$, o internamento psiquiátrico vem perdendo força significativa como medida de tratamento para os transtornos mentais. As frequentes denúncias por maus-tratos e pela subtração dos direitos humanos das pessoas internadas em hospitais psiquiátricos, bem como o surgimento de outras teorias que explicam, com base em fundamentos sociais, a origem dos transtornos mentais, colocaram em xeque os resultados da dita medida em benefício das pessoas que a recebiam, ao restar evidenciado que não respondia às necessidades de saúde dos enfermos mentais (FORTES, 2010).

Como a loucura esteve historicamente, na maior parte do tempo, associada à periculosidade, alguns países regularam a adoção do internamento não voluntário como providência de caráter terapêutico a assegurar tanto o direito do enfermo, de ser tratado dignamente, quanto o dos demais indivíduos que o direito deve proteger. Um desses países que, inclusive, apresentam uma das legislações mais avançadas nessa área, desde a Constituição até Leis e atos normativos que regulam essa questão, é a Espanha. Entretanto, alguns investigadores têm chamado a atenção para a ocorrência de internamentos arbitrários ou não completamente fundamentados em necessidades terapêuticas (AMARANTE, 1998; BUENO; REVUELTA, 1988; LÓPEZ, 2007; TEALDI, 2008; VEGA; GONZÁLEZ; AUGUSTÍN, 2010).

Visando promover e estimular o debate nesta seara, este estudo teve como objeto a investigação da jurisprudência das Audiências Provinciais da Comunidade Autônoma da Catalunha, Espanha, sobre os pedidos de internamento não voluntário de pessoas, supostamente portadoras de transtornos psíquicos, a fim de entender como esta questão, mais médica do que judicial, tem sido enfrentada pela justiça espanhola. Os objetivos da pesquisa consistiram em descrever as variáveis apresentadas nas resoluções judiciais de $2^{\underline{a}}$ Instância relacionadas aos internamentos não voluntários por 
razão de transtorno psíquico e em analisar os posicionamentos dos juízes à luz dos princípios bioéticos enunciados por Beauchamp e Childress.

A Ley General de Sanidad (ESPAÑA, 1986) estabelece as normas e diretrizes gerais do sistema público de saúde na Espanha. Reserva um capítulo específico para a saúde mental. Seu artigo 20 demonstra, explicitamente, a intenção política de redução da hospitalização psiquiátrica, bem como o estímulo ao tratamento ambulatorial e comunitário das pessoas portadoras de transtornos mentais. Osório (2005) sustenta que a reforma psiquiátrica espanhola, iniciada em 1985, ainda apresenta importantes desafios para a consolidação de um modelo que supere o velho paradigma baseado na abordagem ao transtorno mental como periculosidade e ao seu tratamento como internação asilar.

Ao impactar em matérias sociais, legais e que dizem respeito ao direito à saúde e a sua relação com a autonomia para gerir a própria vida, com a liberdade de escolhas e o convívio social, o internamento psiquiátrico não voluntário, por razão de transtorno psíquico, constitui campo privilegiado para a investigação bioética, disciplina que "trata de las cuestiones éticas relacionadas con la medicina, las ciencias de la vida y las tecnologías conexas aplicadas a los seres humanos, teniendo en cuenta sus dimensiones sociales, jurídicas y ambientales" (UNESCO, 2005, p. 3).

A bioética, na visão de Potter (1971, p. 1), como "o conhecimento de como usar o conhecimento", pode ser um norteador importante não só na prática clínica do internamento psiquiátrico forçoso, mas também na prática judicial, por promover a ponderação de valores morais, cujo fim último deveria ser a formação de atitudes e políticas para o alcance do bem social, que deve considerar, sobretudo, a garantia do bem individual do portador de transtorno mental.

\section{Métodos}

A pesquisa configurou-se como quali-quantitativa. Foi realizada por meio da utilização das bases de dados do sistema Aranzadi, ${ }^{1}$ plataforma da rede mundial de computadores que contém, em meio eletrônico, desde fins do ano de 1978, as resoluções judiciais de todos os tribunais espanhóis e de alguns tribunais europeus. ${ }^{2}$

Foram coletadas as resoluções judiciais proferidas em $2^{\underline{a}}$ Instância, no período de janeiro de 2000 a janeiro de 2011, das audiências provinciais da Comunidade Autônoma da Catalunha, integrada pelas províncias de Barcelona, Girona, Lleída e Tarragona. A data terminativa escolhida coincide com o décimo primeiro 
aniversário da Lei de enjuiciamiento civil - LEC, Lei oำ 1, de 7 de janeiro 2000, que teve parte do inciso I de seu artigo no 763 , o qual dispóe sobre o internamento não voluntário por razão de transtorno psíquico, declarado inconstitucional, em dezembro de 2010, após dez anos de vigência do mesmo (ESPAÑA, 2000).

As audiências provinciais são tribunais de justiça que julgam os casos demandados em seus respectivos âmbitos territoriais. São órgãos colegiados que podem julgar em $1^{\underline{a}}$ Instância determinados delitos penais e conhecer recursos de apelação contra decisões ditadas pelos juizados de 1를 Instância de suas províncias, nas áreas civil e penal (ESPAÑA, 1985).

A escolha pelas audiências provinciais deu-se pelo fato de a LEC estabelecer restrições à vista de peças processuais que possam expor a vida privada das partes, como é o caso dos transtornos psiquiátricos. Como suas jurisprudências se encontram em meio eletrônico (já tendo recebido pelos tribunais o devido tratamento para os casos que tramitam em segredo de justiça, bem como para o resguardo dos nomes verdadeiros das partes implicadas no processo), o acesso é público, o que permitiu às pesquisadoras obterem todas as resoluçōes referentes à temática no período citado. Além disso, são essas audiências as instâncias competentes para julgar os recursos em $2^{\underline{a}}$ Instância, expressando a posição predominante do Poder Judiciário em suas respectivas províncias, sendo ainda possível verificar o nível de concordância dos juízes em suas decisões, já que, nessas resoluções, constam também as decisões de $1^{\text {a }}$ Instância. Menciona-se, ainda, que não foram encontrados processos em segredo de justiça.

$\mathrm{Na}$ busca das resoluções, utilizaram-se as expressões-chave: "internamiento no voluntario por razón de trastorno psíquico", "internamiento no voluntario", "internamiento involuntario", "internamiento psiquiátrico" e "internamiento forzoso". Consideraram-se apenas as resoluçôes concernentes ao âmbito do processo civil.

Foram encontradas 35 resoluçôes, das quais se retiraram as seguintes variáveis para o preenchimento de um banco de dados no programa Microsoft Access 2007:

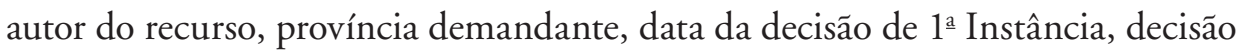
de 1a Instância, principais argumentos constantes da decisão de 1ª Instância, pedido do autor do recurso, justificativa apresentada, situação de saúde da pessoa afetada pela decisão judicial, posição do Ministério Fiscal (MF), data da decisão de $2^{\underline{a}}$ Instância, decisão de $2^{\underline{a}}$ Instância, argumentos apresentados na decisão de $2^{a}$ Instância, participação de médicos na $1^{\underline{a}}$ e na $2^{2}$ Instâncias, exame e audiência judicial da pessoa afetada pela decisão, e incapacitação prévia ao recurso. 
As variáveis foram categorizadas e analisadas por meio da estatística descritiva. Entretanto, a variável "argumentos apresentados na decisão de 2ª Instância" recebeu tratamento qualitativo, empregando-se como método a categorização por ideias centrais, de acordo com o proposto pelo Discurso do Sujeito Coletivo - DSC (LEFÈVRE; LEFÈVRE, 2005), e como referencial teórico de análise, a bioética principialista. Assim, em cada resolução judicial, foram identificados os trechos mais relevantes das falas dos juízes e construídas as ideias centrais desses discursos. Posteriormente, procedeu-se a suas análises à luz da bioética principialista.

Em virtude de ter como segundo objetivo a análise do posicionamento dos juízes e, por isso, basear-se apenas nas resoluções judiciais que expressavam as decisões de $2^{\mathrm{a}}$ Instância, a pesquisa apresenta algumas limitações nos resultados das variáveis objetivas, levantadas com a finalidade de proporcionar uma visão global do objeto de investigação, como os argumentos constantes da decisão de $1^{\underline{a}}$ Instância, o exame judicial da pessoa afetada, a participação de médicos examinadores por instância (forenses ou facultativos) e a posição do MF, pelo fato de não serem mencionadas em grande parte das resoluções encontradas. Contudo, essa circunstância não comprometeu a análise qualitativa das decisões judiciais de $2^{\underline{a}}$ Instância realizada, uma vez que em todas as resoluções encontradas existiam os discursos dos juízes.

\section{Resultados}

As famílias das pessoas afetadas pela decisão judicial, principalmente mães e pais dessas pessoas, foram os autores mais recorrentes no estudo, sendo responsáveis por $40 \%$ dos recursos impetrados. Em segundo lugar estão, com $31,43 \%$, as próprias pessoas afetadas pela decisão judicial, ou seja, as pessoas de cujo internamento se trata. O MF (com papel semelhante ao do Ministério Público brasileiro, ou seja, de fiscalizar a aplicação da Lei) e as instituições de saúde tiveram papel menos preponderante na respectiva autoria, representando, em conjunto, $28,57 \%$ dos autores.

A província de Barcelona figurou em 33 das 35 resoluções analisadas. $\mathrm{O}$ decurso médio de tempo entre as decisōes de $1^{\underline{a}}$ e de $2^{\underline{a}}$ Instâncias foi de 310 dias, ou seja, quase um ano, compreendido entre os extremos de 45 e 681 dias. A maior parte das decisóes de $1^{\mathrm{a}}$ Instância, $51,42 \%$, foi desestimatória quanto ao pedido de internamento. Cabe destacar que $22,86 \%$ dessas decisóes estimaram 
desinternaçōes e $20 \%$ desestimaram a prorrogação do internamento, sendo que em 74,29\% das resoluções analisadas, não constava o embasamento jurídico utilizado para proferi-las. Entretanto, deve ser destacado que $20 \%$ das resoluçōes que desestimavam os pedidos de internamento em $1^{\underline{a}}$ Instância faziam-no por considerar que o retratado em juízo era meramente uma situação assistencial, que requeria apenas supervisão da pessoa afetada pela decisão e não, propriamente, um transtorno mental que requeresse o internamento como medida de tratamento.

Os pedidos dos autores dos recursos variaram entre internamento $(51,42 \%)$, desinternação $(25,72 \%)$ e prorrogação de internamento (20,00\%), ocorrendo apenas um caso $(2,86 \%)$ de revogação de auto de internamento, em uma ocasião, na qual a pessoa afetada pela decisão, mesmo já havendo recebido alta, não concordava com a medida judicial aplicada. As justificativas desses autores foram variadas, situando-se entre aquelas que defendiam argumentos para a internação e as que procuravam demonstrar a inadequação desse procedimento no caso em relevo. No primeiro caso, as mais recorrentes foram a alegação de a pessoa padecer de transtornos mentais desde longa data, sendo que o não internamento ou a não prorrogação de seu internamento a colocaria, e também aos cidadãos que o direito deve proteger, em situação de desproteção, e a nula consciência de sua enfermidade. No segundo caso, a sustentação da existência de tratamento ambulatorial para o transtorno pelo qual o autor do recurso é afetado, juntamente com a alegação de suposta infração ao artigo nº 763 da LEC, por não haver a intervenção do MF e o exame do médico forense, foram as mais citadas. Contudo, deve ser salientado que quase a metade das resoluções judiciais analisadas não continha as justificativas apresentadas pelos autores.

Quanto às situações de saúde apresentadas, foi constatado que 37,14\% das pessoas afetadas pelas decisões judiciais padeciam de algum tipo de esquizofrenia; $17,14 \%$, de transtornos delirantes; $8,57 \%$, de dependência de drogas; $28,57 \%$, de outros transtornos mentais; e em $8,58 \%$ dos casos, o transtorno não foi mencionado no texto da resolução judicial.

Das decisões judiciais de $2^{a}$ Instância, 46\% desestimaram os pedidos de internamento julgados, percentual inferior ao da $1^{\underline{\underline{a}}}$ Instância. Entretanto, foram desestimadas também $22,86 \%$ das solicitações de desinternação e estimados todos os sete pedidos $(20 \%)$ de prorrogação de internamento. Um ponto de destaque deve ser o grau de concordância entre os juízes e o MF. Foi observado 
que, na maioria das situações analisadas, o juiz desestimou o internamento

ou a desinternação nos processos em que o MF se posicionou contra ambas as situações pleiteadas em juízo.

Outro ponto de destaque foi a concordância entre a $1^{\underline{a}}$ e a $2^{\underline{a}}$ Instâncias quanto às decisões desestimatórias do internamento, demonstrando que, nessa circunstância, o julgamento de $2^{\underline{a}}$ Instância tende a manter o de $1^{\underline{a}}$ e a confirmá-lo. Contudo, quando a demanda impetrada se referiu à desinternação, ocorreu discordância entre essas Instâncias. Enquanto os juízes de $1^{\text {ạa }}$ Instância estimaram oito dos nove pedidos, os de $2^{\underline{a}}$ Instância estimaram somente uma das nove solicitações.

A análise da participação de médicos forenses e não forenses foi outra questão prejudicada porque nem todas as decisóes relatavam, objetivamente, em que instâncias se deu a atuação desses profissionais no exame da pessoa afetada pela decisão. Em mais de 50\% dos textos das decisões de 1a Instância analisados, não havia a informação de participação de um médico no processo; em 34,28\% houve a participação de médicos forenses e em 17,14\%, de médicos não forenses, normalmente médicos que acompanhavam a pessoa afetada pela decisão judicial, havendo ainda a participação de um psicólogo. Na segunda instância, houve menção expressa da atuação de médicos em 14,28\% das situações, o que corresponde somente a cinco do total das 35 resoluções analisadas.

Deve ser salientada a concordância do juiz com o médico forense ou não forense. Nas decisões que fazem menção ao relatório médico, há concordância de $100 \%$ da decisão do juiz com o posicionamento médico. Em 60\% das resoluções judiciais, não havia nenhuma referência sobre o exame e a audiência judicial, em sede recursal, da pessoa afetada pela decisão. Todavia, destas, 38\% foram decisões que negaram o pedido de desinternação ou estimaram a prorrogação do internamento. Menos de 20\% das pessoas afetadas pelas decisóes judiciais de internamento, prorrogação de internamento ou desinternação foram, previamente à tramitação das resoluções analisadas, declaradas incapazes civilmente.

Os argumentos apresentados nas resoluçóes de $2^{a}$ Instância, os quais embasaram as decisões recursais dos juízes das audiências provinciais, foram categorizados em 15 ideias centrais. Suas frequências também foram computadas com a finalidade de revelar o quanto esses conceitos estão presentes no conjunto dos discursos e, assim, nos posicionamentos dos juízes. A tabela que segue apresenta essas ideias. 


\begin{tabular}{lll}
\hline Identificação & Ideias Centrais & $\%$ \\
\hline
\end{tabular}

O internamento não voluntário por razão de transtorno psíquico está amparado pelo artigo 255 do Código de Família da Catalunha, pelo

A artigo 211 do Código Civil Espanhol, encontra-se regulado pelo artigo

763 da Lei de Ajuizamento Civil e artigo 5.1 do Convênio Europeu para Proteção dos Direitos Humanos e Liberdades Individuais.

B

O internamento não voluntário é uma medida não sancionadora nem punitiva, que responde pela existência de uma situação de urgência.

$14,29 \%$

O artigo 17.1 da Constituição Espanhola estatui que a liberdade da pessoa é um direito fundamental e que somente pode ser limitado

C nos casos contemplados pela lei e, nesta situação, na existência de um transtorno psíquico para o qual seja necessária a privação temporal da dita liberdade, como medida de proteção para própria pessoa ou para terceiros.

O relatório do médico forense e/ou não forense aponta a necessidade

D do internamento como medida de tratamento para o transtorno padecido pelo enfermo.

Os relatórios médicos indicam a persistência do transtorno

E psíquico, não existindo razão para a revogação do internamento, o $8,57 \%$ que agravaria a situação clínica do enfermo.

A Lei não limita o internamento a situações agudas, a crises

F concretas ou a situações temporais, deixando sua prescrição ao arbítrio médico, sob o devido controle judicial.

O internamento não voluntário é uma medida cautelar independente

G da existência prévia ou simultânea de um procedimento de incapacidade.

A pessoa afetada pela decisão tem antecedentes psiquiátricos e/ou

H já teve ingressos psiquiátricos, possuindo pouca ou nula consciência de sua enfermidade.

$8,57 \%$

O relatório médico conclui que não há situação urgente que requeira o internamento.

O internamento é uma medida terapêutica e assistencial, atuando o juiz como garantidor dos direitos e liberdades individuais.

O juiz deve basear sua decisão de autorização ou denegação de L um internamento no resultado do exame judicial da pessoa e no relatório de um médico por ele designado. 


\begin{tabular}{clc}
\hline Identificaçáo & \multicolumn{1}{c}{ Ideias Centrais } & $\%$ \\
\hline $\mathbf{M}$ & $\begin{array}{l}\text { O internamento é uma medida para assegurar o seguimento do } \\
\text { tratamento quando não há outra forma de garantir que o enfermo } \\
\text { o cumprirá. }\end{array}$ & $11,43 \%$ \\
& $\begin{array}{l}\text { Há outras vias no ordenamento jurídico espanhol que podem } \\
\text { facilitar o tratamento médico para enfermidades psiquiátricas sem } \\
\text { que haja necessidade de recorrer ao internamento não voluntário. }\end{array}$ & $2,86 \%$ \\
$\mathbf{N}$ & $\begin{array}{l}\text { As explorações judiciais realizadas concluem que é necessário um } \\
\text { internamento urgente como medida de tratamento. }\end{array}$ & $11,43 \%$ \\
& As explorações judiciais realizadas verificaram que não estão & \\
& presentes os requisitos para um internamento não voluntário. & $8,57 \%$ \\
\hline
\end{tabular}

\section{Discussão}

Os resultados quantitativos oferecem-nos um retrato objetivo de como o internamento não voluntário, por razão de transtorno psíquico, tem sido tratado pelo Poder Judiciário da Catalunha. Como consequência, podemos dizer que há pelo menos dez anos, os juízes de $2^{\mathrm{a}}$ Instância da Catalunha vêm se deparando com recursos impetrados por pessoas que pleiteiam o internamento de seus familiares próximos, alegando fundamentalmente a internação como medida de proteção da própria pessoa e de terceiros, e que, na grande maioria dos casos, a esquizofrenia é o transtorno que responde por essa medida. Também pode ser afirmado que as pessoas afetadas pela decisão judicial, pleiteando suas desinternaçôes, figuram em um quantitativo elevado nesses recursos.

A concordância das decisões de $1^{\underline{a}}$ e de $2^{\underline{a}}$ Instâncias, no que se refere às desestimações de internamentos, pode trazer-nos a inferência de que o juiz de $2^{\mathrm{a}}$ Instância "tenta" não internar. No entanto, o mesmo não aconteceu com os pedidos de desinternação, normalmente impetrados pela própria pessoa afetada pela decisão, os quais foram majoritariamente estimados em $1^{\underline{a}}$ e desestimados em $2^{\underline{a}}$ Instância, ocorrendo situação semelhante com a prorrogação do internamento, na qual a desestimação na $1^{\mathfrak{a}}$ Instância foi muito mais recorrente do que na $2^{\mathrm{a}}$.

Esse fato nos leva a concluir que, na $2^{\underline{a}}$ Instância, é menos comum a decisão pelo internamento e pela desinternação, sendo mais frequente a decisão pela prorrogação do internamento. $\mathrm{Na} 2^{\underline{a}}$ Instância, a mudança do status de internado 
para desinternado é menos frequente, o que pode suscitar reflexões sobre as implicações bioéticas dessas decisões judiciais, considerando que um direito fundamental de todo ser humano - a liberdade - está sendo cerceado sob os auspícios de um tratamento para a saúde.

\section{Os princípios bioéticos e as decisões judiciais}

A autonomia pode ser definida como a regulação pessoal de si mesmo, livre, sem interferências externas que lhe pretendam controlar (BEAUCHAMP; CHILDRESS, 1999). É, pois, a capacidade de autodeterminação e autogoverno do sujeito, baseada na liberdade de atuação e na condição de agente dessa atuação. É uma característica inerente a todo ser humano, que obriga seu reconhecimento nos indivíduos como fundamental e estreitamente vinculada aos direitos de dignidade e inviolabilidade (BOLADERAS, 1998). Representa a capacidade de estabelecer fins próprios. $\mathrm{O}$ respeito à autonomia de uma pessoa é assumir que essa pessoa tem o direito de ter opiniōes, valores e crenças próprias, bem como agir de acordo com eles, contanto que essa pessoa seja competente tanto do ponto de vista cognitivo quanto moral e sua atuação não prejudique terceiros.

O exercício da autonomia pressupõe uma decisão livre de influências externas que a determinem (BEAUCHAMP; CHILDRESS, 1999). A determinação de um internamento forçoso fere, aparentemente, o princípio da autonomia desse sujeito, que se vê privado de um direito humano fundamental que poderia ser evocado inclusive para rechaçar o tratamento.

O artigo 17.1 da Constituição Espanhola confere a toda pessoa o direito à liberdade e estatui que ninguém pode ser privado de sua liberdade sem a observância do estabelecido em Lei. Por outro lado, os derrogados artigos n. ${ }^{\circ}$ 255 do Código de Família da Catalunha e n. 211 do Código Civil Espanhol regulavam o procedimento jurídico do internamento não voluntário por razão de transtorno psíquico. Atualmente, o assunto é regulado pelo artigo n. ${ }^{\circ} 763$ da LEC, que reeditou os referidos artigos, mas manteve os requisitos básicos para o processo de internamento não voluntário. O Convênio Europeu para Proteção dos Direitos Humanos e Liberdades Individuais, em seu artigo 5.1, também estabelece critérios para o internamento de um enfermo mental. Esses fundamentos, como constatado na investigação levada a cabo, nas figuras das ideias centrais A e C, são amplamente utilizados pelos juízes em suas sentenças. 
Isso significa que não só se baseiam na Lei para tomar suas decisões, mas também nas questões morais que as subjazem.

No caso dos enfermos mentais, a capacidade para exercer a autonomia está diminuída pelo transtorno mental, o que lhes impede de tomar a melhor decisão para si, optando entre o internamento ou não. Nestas circunstâncias, a Lei determina que todo internamento não voluntário, por constituir uma medida privativa de liberdade, deve ser autorizado judicialmente e que, em situações de urgência, seja efetuado por indicação médica e ratificado pelo juiz, após explorações judiciais (ESPAÑA, 2000).

Não só os enfermos mentais, mas também sua autonomia sempre foram motivo de preocupação das sociedades que, anteriormente aos movimentos de reforma psiquiátrica, recluíam essas pessoas a manicômios com a finalidade de livrar a sociedade de sua presença, considerada incômoda, nociva e incompatível com a vida comunitária. A primeira legislação espanhola sobre isso, Lei de Beneficência, data de 1822. Com a progressiva denúncia de maus-tratos e diversos movimentos pelo respeito aos direitos humanos das pessoas nessas condições, a legislação foi sendo modificada, intencionando conferir maiores direitos aos enfermos mentais, bem como protegê-los. Mas, ao contrário do que ocorre com outros tipos de enfermidade, aos transtornos mentais sempre foi conferido um status de periculosidade, configurando-lhe uma situação na qual o Poder Judiciário deve intervir para resguardar direitos individuais (a saúde do indivíduo) e coletivos (a segurança dos demais membros da sociedade).

A intervenção do Estado (na figura do Poder Judiciário) na autonomia de um indivíduo em eleger determinada forma de tratamento para o transtorno mental que lhe afeta foi, antes de legal, uma escolha moral. As normas jurídicas possuem relação evidente com as normas morais, ainda que não dependam da ética para sua configuração, e ao longo dos séculos, a análise dessas relações tem sido central no pensamento jurídico-filosófico (GONZÁLEZ, 2002). A loucura, historicamente, foi excluída do espaço social, e a sociedade, por meio de seus representantes legislativos, optou por assegurar-lhe uma regulamentação que pudesse proteger a sociedade desse problema social. Por conseguinte, o ordenamento jurídico deve cumprir sua função de controle e organização social.

Embora a própria concepção de autonomia traga, fundamentalmente, a ideia de liberdade de atuar sem causar danos aos demais, deveríamos refletir 
542 quais são os danos que esses indivíduos causam à sociedade e quais os prejuízos que a sociedade lhes causa por excluí-los do convívio comunitário, ao deliberar o internamento como a medida terapêutica mais adequada e ao não lhes proporcionar outras formas de tratar seu transtorno.

Os internamentos psiquiátricos involuntários confrontam e podem confundir liberdade com restriçãao, ajuda com coação, terapia com controle, proteção com contenção, necessidade com conveniência (CALCEDO, 1988). Nas resoluções judiciais analisadas, foi possível verificar que o tempo médio para o proferimento das decisões foi de quase um ano, o que é um período significativamente grande para um indivíduo despojado de sua liberdade por razões não criminais. Quiroga (1986) denunciou que o internamento de uma pessoa por questôes médicas tem sido utilizado de forma ilegítima, para obter a reclusão de pessoa sem crime, sem processo e sem pena. Por esse motivo, os processos que tramitam na justiça sobre essa temática deveriam ter prioridade de julgamento sobre todos os demais.

Caso curioso foi o de um homem que, mesmo tendo recebido alta 20 dias após a determinação do internamento não voluntário, interpôs um recurso pleiteando o revogamento do referido auto, por considerar que a decisão foi concluída com valorações pouco objetivas e razões técnicas inadequadas, sendo o internamento uma medida desproporcional (ESPAÑA, 2002). Uma vez que o objeto de sua ação não era outro senão a revogação do auto que lhe impusera a internação, mesmo que sua revogação não tivesse o condão de modificar o fato de já ter-se submetido à mesma, o posicionamento do autor do recurso demonstra o sentimento de injustiça que lhe causou a decisão judicial.

Dessa forma, a privação de direitos tão importantes como a autonomia e a liberdade, ainda que isso possa ser justificado quando existem razóes legais e morais, deve ser muito bem analisada e contrabalançada com outros princípios prima facie, os quais indicam que uma obrigação deve ser cumprida, a menos que entre em conflito com outra obrigação de importância equivalente ou maior. Por ser uma questão cuja avaliação da necessidade não tem uma reposta unívoca, o internamento não voluntário por razões psíquicas sempre irá desembocar em demanda judicial e colocará o juiz frente a uma questão de axiologia jurídica: quais são os valores/princípios que se devem proteger e como se deve fazer isso? As decisões judiciais mostram que o princípio da autonomia tem sido suplantado pelo da beneficência (que, aliás, parece suplantar todos os outros) e, por esse 
motivo, este último princípio assume prioridade léxica, sendo tal situação questionável. Grande parte das ideias centrais retiradas das decisões judiciais demonstra a relevância que o tratamento dos transtornos mentais, como medida beneficente em prol do enfermo, tem para os juízes.

A beneficência refere-se à ação realizada em benefício de outros, a obrigação moral de atuar em benefício de outros, de ajudá-los a promover seus importantes e legítimos interesses (BEAUCHAMP; CHILDRESS, 1999). As ideias centrais B, D, E, G, H, J, M e O (tabela 1) parecem relacionar-se intimamente com esse princípio. Os sentidos da internação como medida de proteção da pessoa e como medida de tratamento urgente são evidentes nessas unidades de análise, o que nos leva a concluir que o interesse explicitado pelo julgador é a recuperação da saúde do enfermo mental, o que, aliás, não deveria ser outro.

Para os juízes que utilizaram esses argumentos, o internamento psiquiátrico forçoso não é uma medida punitiva nem sancionadora; é uma providência terapêutica e assistencial, adotada em situações de urgência, nas quais haja risco para a própria pessoa e para terceiros, e que priva o afetado pela decisão judicial de sua liberdade temporalmente. A decisão judicial deve ser apoiada pelo parecer de um médico que tenha examinado o paciente e nas explorações judiciais da pessoa enferma, por meio de seu exame e de sua audiência, e ser empregada para assegurar o tratamento do enfermo quando a ele não adere por meio ambulatorial ou quando não há outra forma para garantir seu cumprimento.

O que chama a atenção nesse tipo de posicionamento é a exigência de dois critérios: urgência e risco. Contudo, tanto um quanto o outro são categorias subjetivas, que irão depender não só do quadro psicopatológico de cada paciente, mas também da situação sociofamiliar, do contexto em que se produz o transtorno e da experiência profissional dos examinadores, no caso o médico e o juiz.

Os argumentos dos familiares que figuraram como autores dos recursos também faziam alusão ao risco que o não internamento ou a não prorrogação do mesmo acarretaria para a própria pessoa afetada pela decisão e aos demais cidadãos que o direito deve proteger. Embora os riscos para o indivíduo fossem mencionados em algumas decisões (autoagressividade, piora do estado de saúde), o risco para terceiros, o risco social, não foi clarificado em nenhuma decisão judicial. De fato, pode-se argumentar que um "louco" em crise iminente pode provocar prejuízo a outrem. Porém, a situação de "louco", precedente à crise por 
si só já é um fator incômodo e com o qual a sociedade ainda não conseguiu lidar de outra maneira, senão por meio de seu ocultamento.

Nas poucas resoluções nas quais foram mencionadas as decisões de $1^{\underline{a}}$ Instância, foi possível observar que todas as que desestimavam o internamento o faziam sob a argumentação de se tratar a situação do enfermo mental de uma situação assistencial, que requeria supervisão e não um tratamento em instituição cerrada. Mesmo que o presente estudo não tenha analisado as outras peças processuais, foram verificadas, em não raros textos das decisões, referências às dificuldades que as famílias diziam ter para cuidar de seus enfermos, como: poucos recursos econômicos, intolerância quanto à convivência, impossibilidade de fornecer cuidados e vigilância. Essas situações, por si sós, não deveriam constituir indicações para internar um indivíduo, por mais que a intenção dessa medida fosse beneficente. Por esses motivos, muitos pedidos de internamento foram rechaçados em $1^{\underline{a}}$ e em $2^{\underline{a}}$ Instâncias.

Uma ideia central menos frequente, mas muito importante do ponto de vista ético e legal, é a F, a qual expressa que a Lei não limita o internamento a situações agudas, a crises concretas ou a situações temporais, deixando sua prescrição ao arbítrio médico, sob o devido controle judicial. Embora a Lei realmente não traga de forma explícita essas limitações em seu corpo normativo, esse entendimento é totalmente contrário à prática da psiquiatria reformada, influenciada pelas correntes de Jones, Bonnafé, Cooper e Basaglia, que consideram indicado o internamento somente em situações agudas, de crise ou de urgência e, sempre que possível, limitado ao menor tempo necessário para a estabilização do paciente (AMARANTE, 1998).

Um internamento fora das circunstâncias de urgência e risco não seria beneficente para o enfermo; sê-lo-ia, pois, para terceiros, que transfeririam a parcela de suas responsabilidades para a instituição que levaria a cabo o internamento. Nesse contexto, a internação não tem a finalidade de alcançar o melhor interesse para o paciente, pois tratar o transtorno nessas condições não é o mesmo que buscar a recuperação da saúde do indivíduo. Pelo contrário, internar alguém que não necessite possivelmente acarretará danos a esse sujeito. Assim, uma decisão aparentemente baseada na beneficência de sua ação pode entrar em conflito com outro princípio bioético: a não maleficência. 
A não maleficência, que provém da máxima primum non nocere (em primeiro lugar não causar dano), obriga-nos a não causar dano intencionalmente a ninguém, e é totalmente distinta da obrigação de ajudar aos demais. É não obstaculizar, não impedir que se cumpram os interesses de uma parte em virtude de atos e condições autolesivos, intencionados ou não, da outra parte (BEAUCHAMP; CHILDRESS, 1999). Enquanto o princípio da beneficência é positivo, ou seja, implica fazer algo para promover o bem ou evitar o mal, o da não maleficência pode ser positivo ou negativo, resultar em uma ação ou omissão com a finalidade de não causar prejuízo a outrem.

As ideias centrais I, L, N e P (tabela 1) evidenciam de maneira incontroversa a presença do conceito de não maleficência. A inexistência de urgência constatada pelo médico, bem como a ausência de outros critérios para o internamento não voluntário (ainda que esses critérios não tenham sido explicitados em todas as decisóes judiciais que desestimaram o internamento), manifestos no exame ocular (para constatar o estado do paciente) realizado pelo próprio juiz e nos relatórios médicos, foram as fundamentações empregadas para demonstrar que o internamento não voluntário não estaria adequadamente indicado e, por esse motivo, poderia constituir medida prejudicial ao enfermo por privar-lhe de sua liberdade e submetê-lo a um tratamento obrigatório (que na maioria dos casos inclui a administração de medicamentos psicotrópicos) e, igualmente, não adequado.

Cabe destacar que, nos processos analisados, houve concordância de 100\% das decisões judiciais com os pareceres dos médicos que examinaram os enfermos, o que, do ponto de vista clínico, é a medida mais acertada, visto que os juízes carecem de conhecimentos na área médica para decidirem sozinhos, sem o embasamento requerido, sobre a necessidade de um tratamento que priva o paciente de sua liberdade de escolha. Nessa situação, o médico tem uma responsabilidade especial, pois estará indiretamente definindo a decisão judicial.

Outra questão que mereceu relevo foi o fato de não ter sido mencionado o exame da pessoa afetada pela decisão em 38\% das decisões que desestimaram o desinternamento ou prorrogaram a internação. O ordenamento jurídico espanhol vigente não detalha o trâmite do processo de internamento não voluntário nos casos de recursos. Contudo, pode-se deduzir que, se o exame e a audiência da pessoa afetada pela decisão são um dever judicial prévio à autorização ou ratificação do 
internamento, os mesmos deveriam ocorrer nas situações de recursos quanto à manutenção ou não desses internamentos, atos necessários para a certificação de que a medida ainda é apropriada e de que não está causando danos ao paciente.

A preocupação em não causar dano ao paciente foi fortemente evidenciada na ideia central $\mathrm{N}$, na qual o juiz expõe sobre a existência de outros meios para tratar enfermidades psiquiátricas, sem que para isso seja necessário acionar a medida de internamento. Embora não tenha especificado em sua decisão que outras vias seriam essas, não é difícil supor que a referência possa ter sido feita ao tratamento ambulatorial involuntário civil (TAI). Mesmo que não haja uma legislação específica na Espanha, essa medida já vem sendo empregada por alguns juízes das audiências provinciais espanholas (LAZCANO, 2010) quando, por meio de argumentos médicos nos contextos apresentados, se convencem de que é uma alternativa à internação não voluntária, devolvendo o enfermo a seu meio comunitário, ao mesmo tempo em que o obriga a seguir um tratamento para recuperação de sua saúde ou controle de seu transtorno.

Todavia, o TAI não está regulado no ordenamento jurídico espanhol e, desde o ano de 2004, é alvo de intensa polêmica entre magistrados, MF, associações médicas e sociedade civil. Ainda que o objetivo do presente artigo não seja enfocar esse assunto, cabe fazer uma importante consideração acerca do TAI: um de seus fundamentos baseia-se na obrigação social de atender e ajudar os enfermos mentais graves, ainda que eles não desejem (CARTAGENA, 2006). Essa obrigação social traz subjacente uma noção de justiça, haja vista que atribui à sociedade o dever de cuidar de seus enfermos mentais de uma forma que respeite sua dignidade, ou seja, sua forma de ser no mundo.

Segundo Beauchamp e Childress (1999), o princípio de justiça diz respeito ao trato igual, equitativo e apropriado à luz do que se deve às pessoas ou do que é propriedade delas. Uma situação de justiça apresenta-se sempre que uma pessoa é credora de benefícios em virtude de suas qualidades ou de circunstâncias particulares. Quem tem uma exigência válida, baseada na justiça, tem um direito e, portanto, deve-se algo a essa pessoa.

De acordo com a Teoria Igualitarista de Justiça (DANIELS, 1985), baseada no princípio da igualdade justa de oportunidades, a sociedade tem a obrigação de eliminar ou reduzir as barreiras que impedem a igualdade justa de oportunidades 
entre os indivíduos, uma obrigação que se estende fundamentalmente aos programas que corrigem ou reduzem essas desvantagens, como é o caso da assistência à saúde. As doenças, sobretudo as mentais, são restrições que podem impedir ou limitar as oportunidades das pessoas para realizar seus planos de vida. Dessa forma, se os sistemas de saúde podem corrigir ou minimizar essas desvantagens, deveriam estar orientados para essas necessidades, ou seja, para as condições requeridas para se restaurar os níveis adequados de saúde.

Daniels (1985) assinala, ainda, que as ações de saúde que têm efeito significativo sobre a prevenção de doenças, sobre a limitação do que reduz as funções normais do organismo humano (como, por exemplo, o tratamento para os transtornos mentais) ou sobre o que compensa uma redução, deveriam ser priorizadas no desenho dos sistemas de saúde e na distribuição da atenção à saúde. O objetivo desse desenho seria assegurar a justiça através da igualdade justa de oportunidades por meio da distribuição dos recursos sanitários.

O acesso à assistência sanitária entre as pessoas é desigual por várias questôes, que vão desde a acessibilidade ao serviço necessitado (renda, transporte, localização da instituição sanitária, disponibilidade do serviço), até o desenho de um modelo estrutural e assistencial que realmente atenda às necessidades existentes, sobretudo as que são colocadas pelos transtornos mentais. Ao contrário de outras áreas da medicina em que o conhecimento está bastante avançado, como no caso das vacinas, genética, biotecnologia, nanotecnologia, a psiquiatria estancou no desenvolvimento de medicamentos que, mesmo tendo melhorado significativamente o tratamento dos transtornos mentais, não provou ser suficiente para garantir a melhoria da qualidade de vida das pessoas que padecem de transtornos mentais. Avançou-se muito nas pesquisas de medicamentos psicotrópicos para o controle dos transtornos mentais, mas muito pouco se evoluiu no que Merhy (2002) chama de tecnologias leves, relacionais, que são aquelas que se associam à relação profissional-paciente com base no acolhimento, vínculo, autonomização e responsabilização. Isso significa dizer que é necessário pensar e realizar desenhos sanitários que respondam à problemática colocada pelos transtornos mentais, que é a de oferecer o melhor tratamento para as pessoas por ela acometidas, respeitando seus direitos fundamentais e constitucionais, como a liberdade, o direito à convivência comunitária e a participação social, sem os muros de uma instituição que acaba excluindo-as da sociedade. 
Diniz e Guilhem (2002) advertem-nos que o conceito de justiça traz à tona a resolução de conflitos existentes entre as reivindicações coletivas e os interesses individuais, e que as regras de justiça serviriam para equilibrar esses, muitas vezes, conflituosos interesses. O internamento psiquiátrico constitui um caso de violação desse princípio de justiça quando se promove pelo interesse da medicina, do Estado ou dos familiares, em lugar dos melhores interesses do paciente. Essa violação não existe somente quando o internamento não voluntário é realizado nessas condições, mas é perene por não haver investimentos que ofereçam alternativas a essas pessoas.

Ao não serem oferecidos outros meios para o tratamento dos enfermos mentais que não tenham condições de decidir por si mesmos sobre seu internamento, não restará aos juízes outras opções legais que não o internamento não voluntário. $\mathrm{Na}$ prática clínica, o internamento é sempre o último recurso. Mas se não existirem materialmente outros recursos (e mesmo se existirem, o enfermo não tiver acesso a eles), o internamento sempre será adotado com base nessa justificativa injusta.

A presente pesquisa demonstrou que, efetivamente, os juízes se apoiam nos pareceres emitidos pelos médicos examinadores (forenses ou facultativos) e que, em todos os casos, houve total concordância da decisão judicial com a decisão médica. Tal fato demonstra que a decisão é, indiretamente, médica. Por esse motivo, pouco resolverá a existência de dispositivos legais que assegurem um tratamento não hospitalar a enfermos mentais graves e com pouco ou nula consciência de sua enfermidade se os médicos não chancelarem essas alternativas terapêuticas.

Logo, é necessário que a medicina invista em pesquisas e na implementação de novos métodos que privilegiem o tratamento comunitário da pessoa portadora de transtorno mental, isto é, em estabelecimentos extra-hospitalares substitutivos à internação, mesmo que este seja obrigatório, uma vez que o internamento não voluntário também o é, com o ônus de privar a pessoa de alguns de seus direitos fundamentais e da convivência em seu meio social. Igualmente, deve-se investir na avaliação desses métodos para que seja possível conhecer seu grau de eficiência na melhoria da qualidade de vida dos enfermos mentais. Essa é uma importante forma de assegurar a igualdade justa de oportunidades por meio da distribuição dos recursos sanitários necessários à promoção da saúde das pessoas acometidas por transtornos mentais. 


\section{Considerações finais}

De acordo com os estudos da OMS (2010), os transtornos mentais tendem ao aumento. Por ser uma questão que interfere na ordem social (e até mundial), sua abordagem deve envolver vários setores da sociedade. Essa exigência é ainda mais categórica quando as decisões que devem ser tomadas afetam as gerações presentes e as futuras. $\mathrm{O}$ tratamento das pessoas com transtornos mentais é uma questão que afeta esta e as próximas gerações por definir, em alguma medida, o tipo de sociedade que se está construindo. Nesse contexto, pode a bioética trazer contribuições importantes, ao propor princípios para usar o conhecimento científico, técnico e legal.

Na presente pesquisa, o princípio da beneficência da internação não voluntária parece prevalecer sobre todos os outros. Entretanto, a internação como uma medida de proteção e tratamento deve obedecer a critérios clínicos e judiciais rigorosos. Considera-se que a autonomia de um enfermo mental estará prejudicada em virtude de seu transtorno e, por isso, a decisão sobre um tratamento privativo de sua liberdade deverá levar em conta o melhor interesse para o paciente, uma vez que uma internação não voluntária, sem indicações terapêuticas adequadas, pode ferir o princípio da não maleficência.

O Poder Judiciário, acionado nessa esfera, não pode prescindir de uma análise prioritária desses casos sobre todos os demais, de examinar e ouvir a pessoa afetada pela decisão, de observar o limite, às vezes tênue, entre uma necessidade de assistência social e uma real necessidade de saúde, tendo nos princípios bioéticos norteadores importantes para alcançar o melhor interesse do paciente, o qual deve ser o maior interesse social. Isto significa que a recuperação do paciente, promovida pelos melhores e mais humanos meios de tratamento que se possa ofertar, deve ser o principal interesse social, tendo em vista que o fim último de uma sociedade é o bem comum, ou seja, o bem de todos e o desenvolvimento humano de cada um de seus membros.

Uma vez que é o médico, indiretamente, quem define ou não o internamento não voluntário, este deverá também atuar com base nos princípios bioéticos. Nesse sentido, é peremptório que os médicos não só desenvolvam, mas também admitam formas alternativas para o internamento, como o TAI, por exemplo, e outros que efetivamente constituam opções para os enfermos mentais. 
A aplicação dos princípios bioéticos também pode ser exigida do Estado Espanhol, uma vez que sua constituição lhe imputa o papel de financiador e provedor de serviços de saúde para todos os cidadãos. Logo, necessita planejar um sistema de saúde que efetivamente responda às necessidades requeridas pelas pessoas portadoras de transtorno mental e, ao mesmo tempo, proteja e promova seus direitos humanos, respeitando, assim, o princípio bioético da justiça. Devese ter em conta que isso é tanto devido aos enfermos mentais, pois eles não têm as mesmas oportunidades que os "sãos" para realizar seus objetivos de vida, como é um dever do Estado, que deve atuar para corrigir ou reduzir essas desigualdades. ${ }^{3}$

\section{Referências}

AMARANTE, P. Loucos pela vida: A trajetória da reforma psiquiátrica brasileira. 2. ed. Rio de Janeiro: Fiocruz, 1998.

BEAUCHAMP, T.L.; CHILDRESS, J.F. Principios de ética biomedica. Barcelona: Masson, 1999.

BOLADERAS, M.C. Bioética. Madri: Síntesis, 1998.

BUENO, S.D.; REVUELTA, J.L.G. de R. Aspectos Legales de los Internamientos Psiquiátricos. Psiquis, Madri, v. 9, p. 300-313, 1988.

CALCEDO, O.A. En tomo al internamiento psiquiátrico. Actas Luso-Esp. Neurol. Psiquiatr., Madri, v.16, n.1, p.59- 62, 1988.

CARTAGENA, F.S. Tratamiento Ambulatorio Involuntario: tal vez sí, pero. Cuad. Psiquiatr. Comunitaria, Madri, v.6, n.1, p.47-54, 2006.

DANIELS, N. Just Health Care. New York: Cambridge University Press, 1985. p.34-58.

DINIZ, D.; GUILHEM, D. O que é bioética? São Paulo: Brasiliense, 2002.

ESPAÑA. Ley Orgánica del Poder Judicial no 6, de 1 de Julio de 1985. Disponível em: $<$ http://noticias.juridicas.com/base_datos/Anterior/r28-lo6-1985.11t4.html\#c4>. Acesso em: 29 nov. 2011.

. Ley General de Sanidad $n^{\circ}$ 14, de 25 de abril de 1986. Disponível em: <http:// www.bioeticanet.info/relacion/LeyGenSan86.pdf>. Acesso em: 04 abr. 2011.

Ley $n^{\circ} 1$ de Enjuiciamiento Civil, de 7 de enero de 2000. Disponível em: < http:// noticias.juridicas.com/base_datos/Privado/14-2011.html>. Acesso em: 29 nov. 2011.

Audiencia Provincial De Barcelona (Sección 18a). Auto de 21 octubre 2002 - JUR\2003\23711. Disponível em: < http://www.westlaw.es/wles/app/nwles/search/ template?tid=jurisprudencia\#>. Acesso em: 29 nov. 2011.

FORTES, H.M. Tratamento compulsório e internações psiquiátricas. Rev. Bras. Saúde Matern. Infant., Recife, v.10, p.S321-30, dez. 2010. Suplemento 2. 
GONZÁLEZ, M.C. ¿Por qué bioética y derecho? Acta Bioethica, Santiago do Chile, ano 8, n.2, p.183-193, 2002.

LAZCANO, G.P. Tratamiento ambulatorio involuntario de carácter civil. Una revisión. Cuad. Med. Forense, Sevilla, v.16, n.1-2, p.87-97, 2010.

LEFÈVRE, F.; LEFÈVRE, A.M. C. $O$ discurso do sujeito coletivo. Um novo enfoque em pesquisa qualitativa (desdobramentos). Caxias do Sul: EDUCS, 2005.

LÓPEZ, S.C. El proceso de internamiento no voluntario por razón de trastorno psíquico. Revista de Derecho UNED, Madri, n.2, p.175-225, 2007.

MERHY, E.E. Saúde: A cartografia do trabalho vivo. São Paulo: Hucitec, 2002.

ORGANIZACIÓN DE LAS NACIONES UNIDAS PARA LA EDUCACIÓN, LA CIENCIA E LA CULTURA (UNESCO). Declaración universal sobre Bioética y Derechos Humanos, de 19 de outubro de 2005. Disponível em: <http://www.bioeticanet.info/ documentos/DecUBio_DHesp06.pdf>. Acesso em: 28 fev. 2012.

ORGANIZACIÓN MUNDIAL DE LA SALUD. Informe sobre la salud en el mundo 2001. Salud mental: nuevos conocimientos, nuevas esperanzas. Francia: Sadag, 2001.

. Tratamiento farmacológico de los trastornos mentales en la atención primaria de salud. Washington: Organización Panamericana de la Salud, 2010.

OSÓRIO, F.M. Veinte años de reforma psiquiátrica: panorama del estado de la psiquiatría en España de los años 1970 a los 2000: de un pensamiento único a otro. Rev. Asoc. Neuropsiq., Madri, v.25, n.95, p.69-81, 2005.

POTTER, V.R. Bridge to the Future. New Jersey: Prentice-Hall, 1971.

QUIROGA, J.L.B. de. El internamiento de los enajenados. Poder Judicial, Madri, n. 4, p. 49-67, 1986.

TEALDI, J.C. Bioética y derechos humanos en psiquiatría. Rev. Colomb. Psiquiat., Bogotá, v.37, n.2, p. 247-262, 2008.

VEGA, C.V.; GONZÁLEZ, R.M.B.; AUGUSTÍN, A.F. Internamientos psiquiátricos. Aspectos medicolegales. Aten. Primaria, Barcelona, v.42, n.3, p.176-182, 2010.

\section{Notas}

${ }^{1}$ http://www.westlaw.es/wles/app/nwles/search/template?tid=jurisprudencia\#

${ }^{2}$ Agradecimentos à professora Margarita Boladeras, ao juiz de direito e professor Carlos Villagrasa, ambos da Universidade de Barcelona, à médica forense Esperanza Gómez e a Gema Vico Fernández, que colaboraram na realização desta pesquisa; e ao programa de Mobilidade Internacional Santander, que a financiou.

${ }^{3}$ R.T. Salvatori elaborou o desenho da pesquisa, coletou os dados, realizou análise da pesquisa e redigiu o manuscrito. C.A.A. Ventura participou da análise e redação do manuscrito. 


\section{Abstract}

\section{Civil non-voluntary hospitalizations by reason of mental disorders at Catalonia: an analysis of judicial decisions in light of bioethics}

Non voluntary hospitalizations due to mental disorders are a therapeutic measure that should ensure either the right of the patient to be treated with dignity, as well as the safety of the other individuals who have the right to be protected. However, some researchers have called attention to the occurrence of hospitalizations not completely based on therapeutic needs. Thus, this study had as its investigation object the jurisprudence of the Catalonia/Spain Independent Community Court on the demands of non voluntary hospitalization of people with mental disorders. This research aimed to describe the variables presented in the resolutions of second instance Courts related to non voluntary hospitalizations due to mental disorders and to analyze the judges' position in the light of bioethical principles. Descriptive statistics and categorization of central ideas were employed as the analysis method, according to the Collective Subject Speech. The judges of Catalonia are facing the demand of people aiming at hospitalizing their family members claiming that hospitalization is a protection measure to the patient, whom, in most cases, is diagnosed with schizophrenia. Fifteen central ideas were identified on judicial decisions, analyzed according to the bioethical principles of principlism. The principle of beneficence seems to outshine all the others in judicial decisions. Authors concluded that not only the Justice System, but the society, medicine and the State play important roles in the approach to this issue.

Key words: compulsory hospitalization; person with mental disorders; justice system; bioethics. 